\title{
Bilayer repair technique with mesh in petit lumbar hernia
}

\author{
๑Ramazan Topcu ${ }^{1}$, ๑İsmail Sezikli ${ }^{1}$, ๑Hülya Topcu ${ }^{2}$ \\ ${ }^{1}$ Hitit University, Faculty of Medicine, Department of General Surgery, Çorum, Turkey \\ ${ }^{2}$ Hitit University, Faculty of Medicine, Department of Anesthesia and Reanimation, Çorum, Turkey
}

Cite this article as: Topcu R, Sezikli İ, Topcu H. Bilayer repair technique with mesh in petit lumbar hernia. Anatolian Curr Med J 2021; 3(4); 310-314.

\begin{abstract}
Aim: Lumbar hernias are rare; Petit's lumbar hernia (PLH), which is among them, is a rarer hernia type. Surgical repair is a standard treatment after the diagnosis of lumbar hernia. Controversy continues regarding the surgical technique of repairing Petit's lumbar hernia. With this study, we aim to share short term results we obtained from the application of bilayer repair technique with mesh (BRTM), which is a new method in petit lumbar hernia treatment.

Material and Method: Five patients who were diagnosed with lumbar hernia and treated between 2017 and 2020 were examined retrospectively.

Results: Most patients consisted of women $(n=4)$. The mean age was 58.2 years. As for the etiological reason of the disease, 3 patients were trauma-related and 2 patients were previous operations-related. The petit lumbar hernia defect diameter was 6.42. In all patients, BRTM was used. The mean length of hospitalization was 3.6 days. The mean follow-up duration was 13.8 months. There was no recurrence in any of the patients after follow-up.

Conclusion: PLH requires a difficult management from diagnosis to treatment. Thanks to such a strong BRTM, not merely tissue integrity can be ensured, but also anatomical structures will become more organized, and intra-abdominal pressure will be evenly distributed to the preperitoneal area, creating a suspensory mechanism, also, since recurrence will be minimized, we predict that the surgery operation can be performed safely through BRTM in petit lumbar hernia. To support this technique, long-term follow-up and multi-centered studies are necessary.
\end{abstract}

Keywords: Petit lumbar hernia, bilayer repair technique, recurrence

\section{INTRODUCTION}

Even in the times of advanced medicine, it is possible that the rarity of a condition complicates diagnosis and treatment; such a difficulty is found in a lumbar hernia. Lumbar hernia was first proposed by Barbette in the late $17^{\text {th }}$ century, and Garageot published his first case in 1731. Lumbar hernia is a protrusion of intraperitoneal or extraperitoneal contents through a defect in the posterolateral abdominal wall (1). The most common site for lumbar hernia formation is in the upper lumbar triangle (Grynfeltt) and less commonly in the lower lumbar triangle (Petit) (2).

Grynfeltt is an inverted triangle bordered by the $12^{\text {th }} \mathrm{rib}$ superiorly, laterally (anterior obliquely) and quadratus lumborum medial (posterior). The floor is the transverse fascia and the aponeurosis of the transversus abdominis muscle. The roof is the external oblique and latissimus dorsi muscles.

Petit is a smaller right triangle located between the posterior border of the external oblique muscle lateral (anterior), the lateral border of the latissimus dorsi muscle medially (backward), and inferior iliac crest. It consists of the lumbodorsal fascia $(3,4)$.

Twenty percent of lumbar hernias are congenital; 80 percent are acquired (5), which may be either primary (spontaneous) or secondary to trauma or surgery such as nephrectomy, adrenalectomy, liver resection, and abdominal aortic aneurysm repair Posttraumatic and post-incision lumbar hernias are larger and more diffuse than primary lumbar hernias, may not observe the triangular borders outlined above and are therefore often referred to as lateral hernias (5).

Clinically, the most common presentation of a lumbar hernia is a palpable posterolateral mass that increases in 
size with coughing and strenuous activity (6). The mass is usually shrinkable and disappears when the patient assumes the decubitus position (7). The risk of intestinal confinement is low ( $<10$ percent) because the neck hernia is wide at the mouth and is located within the abdominal wall of the hernia $(5,8)$. Lumbar hernias may also present as vague back pain, bowel obstruction, urinary obstruction, pelvic mass, or rarely retroperitoneal or gluteal abscess.

Petit lumbar hernia (PLH) comprises a difficult identification process for surgeons, from diagnosis to treatment in terms of both its rarity and complex anatomical localization (9).

Since lumbar region hernia has risk of strangulation and/ or incarceration, it should be treated surgically (10). It is also a matter of debate what surgical repair technique will end up with. Many techniques such as primary repair, musculoaponeurotic reconstruction, prosthetic mesh repair and laparoscopic repair have been defined (10). Whereas some sources discuss that approximation of these hernia boundaries only is sufficient, other sources suggest that the use of mesh necessarily should be used. Surgical treatment of lumbar hernia may be the best site for tensionfree mesh placement in the preperitoneal region (11).

Lumbar hernias are rare, yet PLH, which is one of them, is a rarer hernia. Discussion on surgical technique of PLH repair still continues. BRTM steps forth more than other techniques in terms of placing sublay mesh, which constitutes the main rationale of the laparoscopic repair technique, increasing the protection at the lower edge of the iliac crest, and strengthening the muscle groups depicting the petit triangle with onlay mesh.

With this study, we aim to share short term results we obtained from the application of BRTM, which is a new method in petit lumbar hernia treatment using both sublay mesh and onlay mesh.

\section{MATERIAL AND METHOD}

The study was approved by the Hitit University Noninterventional Researchs Ethics Committee (Date: 30.04.2021, Application No :2021-80, Decision No: 2021 66). All procedures were carried out in accordance with the ethical rules and the principles of the Declaration of Helsinki.

A total 5 patients who were operated upon the diagnosis of PLH between 2017 and 2021 were investigated retrospectively from the hospital's database and clinical archive. The patients were examined in terms of age, gender, etiology of the disease, side, surgical technique, presence of postoperative complications, radiological imaging, length of hospital stay, follow-up time and recurrence.

\section{Bilayer Repair Technique}

The patient was positioned laterally. A transverse incision was made about $6-8 \mathrm{~cm}$ above the iliac crest and next to the paraspinal muscular system. A hernia sac emerges in the subcutaneous dissection, lower part of the latissimus dorsi muscle, top edge of the iliac crest and medial of the external oblique muscle (Figure 1).

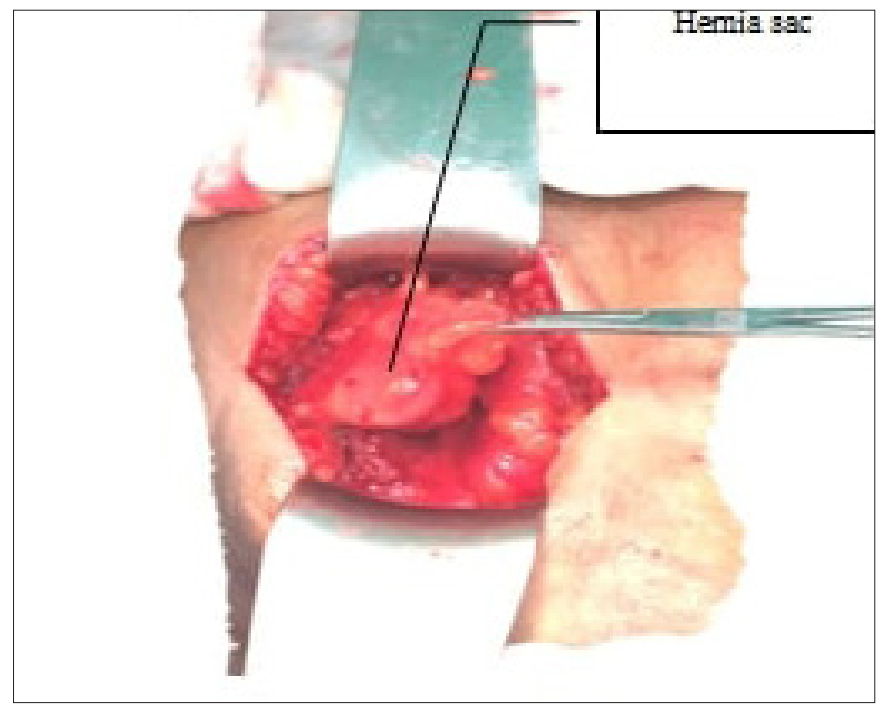

Figure 1. Hernia sac after dissection of subcutaneous tissue

To reduce the hernia defect, the edges of the petit triangle were approximated to the musculoaponeurotic tissues with $2 / 0$ polyglactin. It was placed as "onlay" to close the lower boundary on the iliac crest, and fixation sutures were made on the musculoaponeurotic tissue with $2 / 0$ polypropylene after the musculoaponeurotic reconstruction. The subcutaneous hemovac drain was fixed. Subcutaneous tissue was covered with absorbable $3 / 0$ polyglactin sutures. The skin was closed with $3 / 0$ polyprolen seam and compressed dressing was applied (Figure 3).

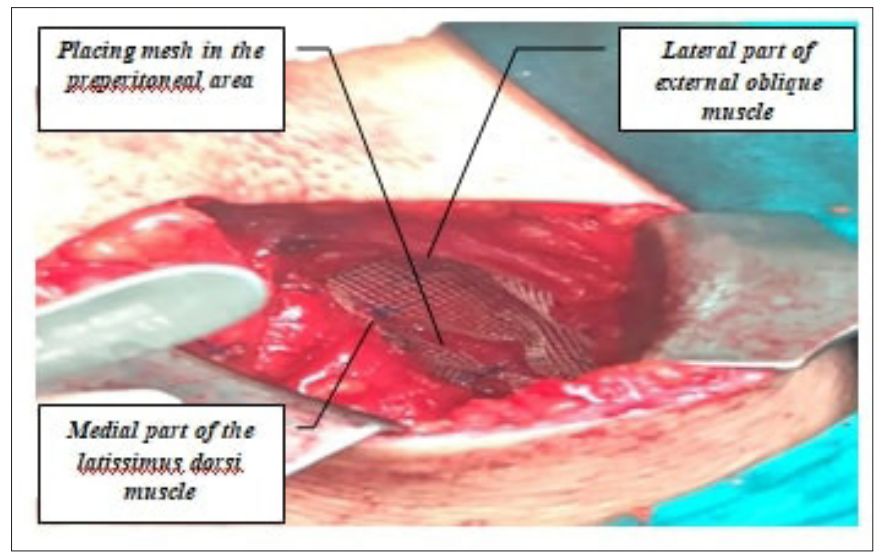

Figure 2. Placement of sublay mesh to preperitoneal area and its detection 


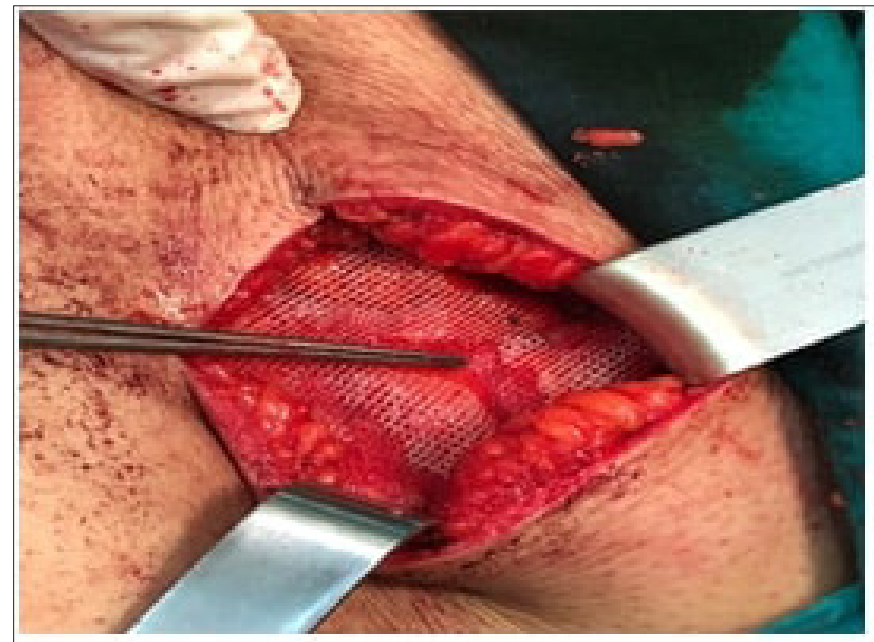

Figure 3. Placing onlay mesh on musculoaponeurotic tissue

\section{RESULTS}

Five patients who were included in the study were operated and followed up by the same surgeon. Most patients consisted of women $(n=4)$. The mean age was 58.2 years. As for the etiological reason of the disease, 3 patients were trauma-related and 2 patients were previous operations-related. The most common reason for hospital admission was left side pain and swelling. For diagnosis, all patients were asked to have computerized tomography (CT) (Figure 4).

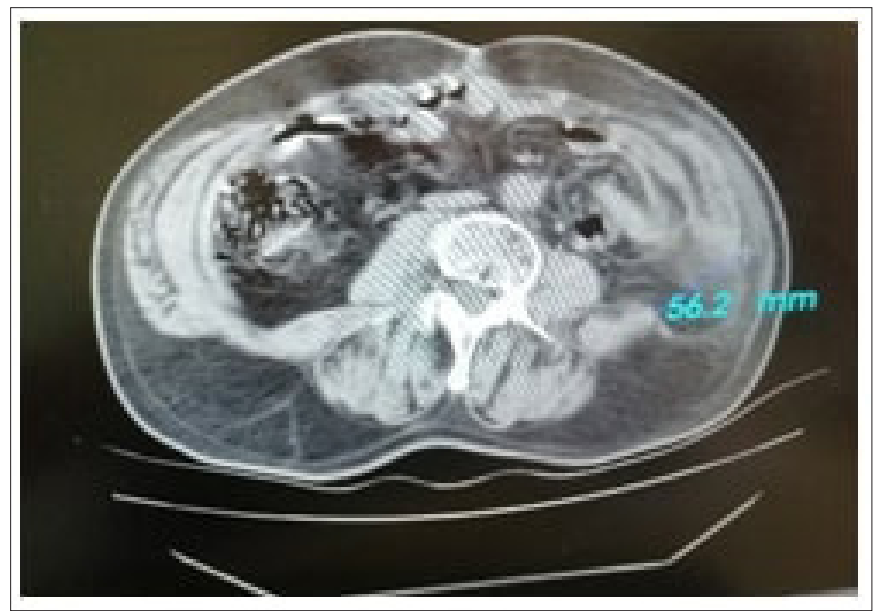

Figure 4. Left lumbar petit hernia in CT
The petit lumbar hernia defect diameter was 6.42. In all patients, the bilayer hernia repair technique with mesh was used. The mean length of hospitalization was 3.6 days. The mean follow-up duration was 13.8 months. There was no recurrence in any of the patients after follow-up. Patients' data are given in Table 1. The drains were removed the third day post-operation. The patients were discharged the third or fourth day in general. The patients have been followed up so far and no complication has been found regarding the wound site. The patients do their daily activities without any limitation in their life.

\section{DISCUSSION}

PLH is defined as herniation of retroperitoneal fat through aponeurosis of the internal abdominal oblique muscle between erector spinae muscles in the lower lumbar triangle. The neck of this hernia is usually large and so, it has lower risk of strangulation compared to other hernias (12). The PLH was defined by Petit in 1783 . The edges of the lower lumbar (Petit) triangle consist of the iliac crest, the sides of the latissimus dorsi muscle, and the external abdominal oblique muscles. In the lower lumbar triangle base, the internal abdominal oblique muscle is seen.

These hernias should not be treated conservatively due to two reasons. The first reason is that about $25 \%$ of these hernias are tended to incarceration and $10 \%$ are tended to strangulation that emerges with acute abdominal features and requires emergency surgery (13). The second one is that these hernias tend to increase in size over time. Surgical repair of a large hernia is difficult. Thus, surgical repair is a preferred treatment without any delay (14).

Petit lumbar hernia requires a difficult management from diagnosis to treatment. Many options such as primary repair, musculoaponeurotic reconstruction, prosthetic mesh repair and laparoscopic repair have been offered as surgical techniques. Surgical treatment is open or laparoscopy and has an equal rate of success (15). Recurrences are known in laparoscopy and open surgical repair. Patients with a risk of recurrence are those who have common lumbar hernias, hernias larger

\begin{tabular}{|c|c|c|c|c|c|c|c|c|c|c|}
\hline Case & Age & Sex & Etiology & $\begin{array}{c}\text { Application } \\
\text { complaint }\end{array}$ & $\begin{array}{c}\text { Defect } \\
\text { diameter } \\
(\mathrm{cm})\end{array}$ & Operation & Recurrence & $\begin{array}{c}\text { Length of } \\
\text { hospital stay } \\
\text { (day) }\end{array}$ & $\begin{array}{l}\text { Postoperative } \\
\text { complication }\end{array}$ & $\begin{array}{c}\begin{array}{c}\text { Follow-up } \\
\text { duration } \\
\text { (month) }\end{array}\end{array}$ \\
\hline 1 & 57 & $\mathrm{M}$ & Trauma & $\begin{array}{l}\text { Left side pain, } \\
\text { swelling }\end{array}$ & 5.6 & BRTM & No & 4 & No & 20 \\
\hline 2 & 58 & $\mathrm{~F}$ & Trauma & $\begin{array}{l}\text { Right side pain, } \\
\text { swelling }\end{array}$ & 6 & BRTM & No & 4 & No & 18 \\
\hline 3 & 76 & $\mathrm{~F}$ & $\begin{array}{l}\text { Previous } \\
\text { operation }\end{array}$ & Left side pain & 8 & BRTM & No & 3 & No & 17 \\
\hline 4 & 50 & $\mathrm{~F}$ & $\begin{array}{l}\text { Previous } \\
\text { operation }\end{array}$ & Right side pain & 6.4 & BRTM & No & 4 & No & 7 \\
\hline 5 & 50 & $\mathrm{~F}$ & Trauma & Right side pain & 6.1 & BRTM & No & 3 & No & 7 \\
\hline
\end{tabular}


than $16 \mathrm{~cm}$ and hernias associated with muscular atrophy (16). Therefore, preference on surgical repair depends on the patient factor and expertise of the surgeon.

Considering the triangle region where the petit lumbar hernia is formed, it becomes a three dimensional space resulting from the destruction caused by the hernia content (11). The repair with sublay mesh alone, which constitutes the main rationale of the laparoscopic repair technique, protects the muscles in this area and the spaces between the muscles. The onlay mesh, making the second layer of the bilayer repair technique, offers a more solid and reliable repair option by increasing the protection in the lower edge of the iliac crest and strengthening the muscle groups that picture the petit triangle. There are two studies on bilayer repair with mesh (BRWM), one of which is case report. The other is the comparison of onlay mesh repair and BRWM in the lumber incisional hernias and is offered as a new technique (17). They stated that this technique could be used on patients safely and they could do recurrence and daily activities without pain in their follow-up. BRWM was applied in all cases of this study and no complication or recurrence was seen in their 13.8 months of follow-up. The patients can easily do their daily activities without any limitation. The current studies support this study.

Before choosing a technique, a full diagnosis must be made so that we know the size, location and content of the defect. Therefore, CT should be performed for the correct planning of the surgery. The operation to be performed on the patient should be decided by considering the benefits or harms of each technique. The anterior approach is highly traumatic and requires extensive dissection to identify the damaged planes and locate the defect, but has the advantage of enabling us to perform a complete parietal reconstruction (18-20). The laparoscopic approach has the advantage of being minimally invasive. It also prevents large dissections, provides the exact location of the lesion and offers excellent visualization, thus avoiding possible lesions to adjacent structures (eg ureter, colon, nerves). However, the laparoscopic approach does not allow for parietal reconstruction or repair under controlled tension (21-30). Therefore, we believe that the double mesh technique should be performed as the repair must be done under a certain degree of tension in order to guarantee an adequate aesthetic and functional result.

It is divided into two types which are congenital (20\%) and acquired (80\%) according to etiology. Congenital herniated disc is common in babies and results from the musculoskeletal defects. Acquired herniated disc can be seen in two types: primary idiopathical $(55 \%)$ and secondary (25\%) PLH developed after trauma, iliac crest graft, infection, etc. (31) In this study, PLHs occurred in 3 patients after a traffic accident and in 2 patients due to previous operations.
They are generally asymptomatic and, either a palpable mass or not, they may cause back pain in the sciatic nerve distribution area. According to Light, back pain is the most possible diagnosis in young women and sporters (32). Also, abscess, hematoma, lipoma, kidney tumors or twitching should be considered in the diagnosis. For screenings, CT is known to be a routine diagnosis technique to examine patients with herniated disc $(8,33)$. Most patients went to the hospital with non-specific complaints, and only one of them went to the emergency service with serious flank pain. This patient had strangulation and was operated under emergency conditions. Although the palpable mass was considered to be lipoma, hematoma or a deep abscess at first, the screening showed that it was a strangulated intestinal structure. There are two points to be considered here. In emergency applications, the presence of trauma becomes important in the differential diagnosis of strangulated lumbar hernia, hematoma or deep abscess, particularly in the palpable mass in the flank area. It should be kept in mind that the palpable structure in the non-traumatic flank area can spring from lumbar hernia and so, an evaluation should be made using CT in the differential diagnosis (13).

In addition, one patient in this study went to the plastic surgery outpatient clinic with the complaint of right flank pain and swelling, and the superficial sonography was compatible with lipoma, and when it was noticed that there was a hernia during excision under local anesthesia, the operation was abandoned and directed to the polyclinic. The mass was palpated in the sitting position. A diagnosis of PLH was made on CT. The gold standard for diagnosing PLH is a CT with $98 \%$ sensitivity. The benefits of CT are; distinguishing the fascial and muscle layers, detecting a defect in one of these layers, evaluating the nature of the possible herniated content and making the differential diagnosis of soft tissue lesions such as lipoma, hematoma (33).

The diagnosis and treatment of lumbar hernias are complicated by its low incidence, resulting in scarce experience and lack of consensus in the literature. Heterogeneity in the population, based on the subdivision in etiology, increases this problem. Publication bias, due to the design of the included studies, might result in an overestimation of the complaints and complications of the patient at presentation, like incarceration. On the other hand, it can cause an underestimation of the recurrence rates. More high-quality research is needed, in which, unfortunately, is the incidence of a lumbar hernia a severely limiting factor. Centralising care for this rare entity would increase specialisation and produce the volumes needed for adequate research. Furthermore, cooperation between specialised abdominal wall centres would increase the awareness of this type of dorsal lumbar abdominal wall hernia. 


\section{CONCLUSION}

Thanks to such a strong bilayer repair technique with mesh, not merely tissue integrity can be ensured, but also anatomical structures will become more organized, and intra-abdominal pressure will be evenly distributed to the preperitoneal area, creating a suspensory mechanism, also, since recurrence will be minimized, we predict that the surgery operation can be performed safely through bilayer repair technique with mesh in petit lumbar hernia. To support this technique, long-term follow-up and multi-centered studies are necessary.

\section{ETHICAL DECLARATIONS}

Ethics Committee Approval: The study was approved by the Hitit University Non-interventional Researchs Ethics Committee (Date: 30.04.2021, Application No :2021-80, Decision No: 2021-66).

Informed Consent: Because the study was designed retrospectively, no written informed consent form was obtained from patients.

Referee Evaluation Process: Externally peer-reviewed.

Conflict of Interest Statement: The authors have no conflicts of interest to declare.

Financial Disclosure: The authors declared that this study has received no financial support.

Author Contributions: All of the authors declare that they have all participated in the design, execution, and analysis of the paper, and that they have approved the final version.

Note: This study was presented as an oral presentation at the $8^{\text {th }}$ National Hernia Congress 8-11 March 2021, virtuals congress (e-congress), OP; 23.

\section{REFERENCES}

1. Burt BM, Afifi HY, Wantz GE, Barie PS. Traumatic lumbar hernia: report of cases and comprehensive review of the literature. J Trauma Inj Infect Crit Care 2004; 57: 1361-70.

2. Wakhlu A, Wakhlu AK. Congenital lumbar hernia. Pediatr Surg Int 2000; 16: 146-8.

3. Cavallaro G, Sadighi A, Paparelli C, et al. Anatomical and surgical considerations on lumbar hernias. Am Surg 2009; 75: 1238.

4. Beffa LR, Margiotta AL, Carbonell AM. Flank and lumbar hernia repair. Surg Clin North Am 2018; 98: 593.

5. Teo KA, Burns E, Garcea G, et al. Incarcerated small bowel within a spontaneous lumbar hernia. Hernia 2010; 14: 539.

6. Liang TJ, Tsai CY. Images in clinical medicine. Grynfeltt hernia. N Engl J Med 2013; 369: 14.

7. Orcutt TW. Hernia of the superior lumbar triangle. Ann Surg 1971; 173: 294.

8. Moreno-Egea A, Baena EG, Calle MC, et al. Controversies in the current management of lumbar hernias. Arch Surg 2007; 142: 82.

9. Cesar D, Valadão M, Murrahe RJ. Grynfelt hernia: case report and literature review. Hernia 2012; 16: 107-1.

10. Bathla L, Davies E, Fitzgibbons RJ Jr, et al. Timing of traumatic lumbar hernia repair: is delayed repair safe? Report of two cases and review of the literature. Hernia 2011; 15: 205-9.

11. Bigolin AV, Rodrigues AP, Trevisan CG, et al. Petit lumbar hernia-a double-layer technique for tension-free repair. Int Surg 2014; 99: 556-9.

12. Petit JL. Traite des maladies chirurgicales, et des operations qui leur convenient. Vol. 2. T.F. Didot; Paris: 1774. pp. 256-8.

13. Ahmed ST, Ranjan R, Saha SB, et al. Lumbar hernia: a diagnostic dilemma. BMJ Case Rep 2014; 2014: bcr2013202085.

14. Esposito C, Settimi A, de Marco M, et al. Congenital lumbar hernia: two case reports and a review of the literature. J Paediatr Surg Spec 2009; 3: 40-2

15. Mingolla GP, Amelio G. Lumbar hernia misdiagnosed as a subcutaneous lipoma: a case report. J Med Case Rep 2009;103: 9322.

16. Moreno-Egea A, Alcaraz AC, Cuervo MC. Surgical options in lumbar hernia: laparoscopic versus open repair. a long-term prospective study. Surg Innov 2013; 20: 331-44.

17. Parikh APK, Parikh P, Vadodariya D, Dave JP, Bhatt JG. Triple mesh technique in repair of recurrent lumbar incisional hernia. Int J Res Med Sci 2019; 7: 4803-6.

18. Lichtenstein IL. Repair of large diffuse lumbar hernias by an extraperitoneal binder technique. Am J Surg 1986; 151: 501-4.

19. Sutherland RS, Gerow RR. Hernia after dorsal incision into lumbar region: a case report and review of pathogenesis and treatment. J Urol $1995 ; 153$ : 382-4.

20. Bolkier M, Moskovitz B, Ginesin Y, et al. An operation for incisional lumbar hernia. Eur Urol 1991; 2052-3.

21. Burick AJ, Parascandola S. Laparoscopic repair of a traumatic lumbar hernia: a case report. J Laparoendosc Surg 1996; 6: 259-2.

22. Woodward AM, Flint L, Ferrara J . Laparoscopic retroperitoneal repair of recurrent postoperative lumbar hernia. J Laparoendosc Adv Surg Tech A 1999; 9: 181-6.

23. Arca MJ, Heniford BT, Pokorny R, et al. Laparoscopic repair of lumbar hernias. J Am Coll Surg 1998; 187: 147-2.

24. Moreno-Egea A, Torralba JA, Morales G, et al. Open vs laparoscopic repair of secondary lumbar hernias: a prospective nonrandomized study. Surg Endosc 2005; 19: 184-7.

25. Bickel A, Haj M, Eitan A. Laparoscopic management of lumbar hernia. Surg Endosc 1997; 11: 1129-0.

26. Heniford BT, Iannitti DA, Gadner M. Laparoscopic inferior and superior lumbar hernia repair. Arch Surg 1997; 132: 1141-4.

27. Shekarriz B, Graziottin TM, Gholami S, et al. Transperitoneal preperitoneal laparoscopic lumbar incisional herniorrhaphy. J Urol 2001; 166: 1267-9.

28. Meinke AK. Totally extraperitoneal laparoendoscopic repair of lumbar hernia. Surg Endosc 2003; 17: 734-7.

29. Postema RR, Bonjer HJ. Endoscopic extraperitoneal repair of a Grynfeltt hernia. Surg Endosc 2002; 167-9.

30. Habib E. Retroperitoneoscopic tension-free repair of lumbar hernia. Hernia 2003; 7: 150-2.

31. Lillie GR, Deppert E. Inferior lumbar triangle hernia as a rarely reported cause of low back pain: a report of 4 cases. J Chiropr Med 2010; 9: 73-5.

32. Light HG. Hernia of the inferior lumbar space. A cause of back pain. Arch Surg 1983; 118: 1077-80.

33. Suarez S, Hernandez JD. Laparoscopic repair of a lumbar hernia: report of a case and extensive review of the literature. Surg Endosc 2013; 27: 3421-9. 